\title{
Kerangka Panduan Efektif Pengajaran Dan Pemudahcaraan (PdPc) Sains Menggunakan Information Communication Technology (ICT) di Sekolah Jenis Kebangsaan Tamil (SJK) (TAML)
}

\author{
Kalaiselvi Shanmugam*, Balamuralithara Balakrishnan \\ Fakulti Seni, Komputeran dan Industri Kreatif, Universiti Pendidikan Sultan Idris, Tanjong Malim, Perak, Malaysia \\ *Corresponding author: p20161000760@siswa.upsi.edu.my
}

\begin{abstract}
The effort of the Ministry of Education of Malaysia (KPM) in strengthening Science, Technology, Engineering and Mathematics (STEM) educations in Malaysia is to increase the source of experts and skilled workforce in the field of research and industry. The inspiration of KPM to empower the strengthening of STEM can be implemented with the availability of ICT. ICT can be a comprehensive tool in teaching and facilitation (PdPc) of science that is complete and inclusive. ICT based science learning is an outcome of the combination of principle and strategy within education and technology domains. ICT has a great potential to spur the learning process and extensive thinking skill among the students since they regularly incorporate the use of ICT in their daily life. However, this mentioned potential has not been fully disclosed in Malaysia. Countries like Finland has a 'road map', meanwhile Canada has a framework for T\&L of science based on ICT. Malaysia still has not developed a 'road map' or a framework as the above for science especially in SJK(T). Besides that, poor achievement in science education is becoming a continuous issue in SJK (T). This case is proven to be true when the results for science subject among the SJK (T) UPSR candidates are dropping since the year 2011. Hence, various elements involving the expansion of ICT based teaching and facilitation of science framework guideline should be identified in Malaysia. The framework guideline will be built based on the Malaysian culture which has the potential to spur success and science competency at the international level.
\end{abstract}

Keywords: ICT, teaching and facilitation of science, students, science teachers

\begin{abstract}
Abstrak
Pengukuhan Pendidikan Science, Technology, Engineering and Mathematics (STEM) di Malaysia merupakan usaha Kementerian Pendidikan Malaysia (KPM) untuk meningkatkan sumber pakar dan tenaga mahir dalam bidang penyelidikan dan industri. Inspirasi dan aspirasi KPM untuk memperkasakan pengukuhan STEM dapat diimplimentasi dengan adanya ICT. ICT mampu menjadi wahana yang komprehensif dalam PdPc Sains yang menyeluruh dan inklusif. Pembelajaran sains yang berasaskan ICT merupakan hasil gabungan prinsip dan strategi antara domain pendidikan dan teknologi. Gabungan kedua-dua domain ini dipercayai berupaya meningkatkan minat pelajar terhadap bidang sains dan meningkatkan pemahaman pelajar. ICT berpotensi tinggi untuk memacu proses pembelajaran dan kemahiran berfikir yang luas kerana murid telah pun biasa dengan penggunaan ICT dalam kehidupan harian. Namun, potensi ini belum dizahirkan di Malaysia. Negara-negara seperti Finland telah mempunyai satu 'road map' manakala negara Kanada mempunyai satu frame work untuk P\&P sains berasaskan ICT. Negara Malaysia masih tidak mempunyai road map atau frame work seumpama itu untuk Sains terutamanya bagi SJK (T). Tambahan pula, prestasi lemah dalam mata pelajaran sains menjadi satu masalah yang berterusan di SJK (T). Keadaan ini terbukti apabila keputusan sains calon UPSR dari SJK (T) semakin menurun sejak tahun 2011. Maka pelbagai elemen yang terlibat dalam pembinaan Kerangka Panduan PdPc sains berasaskan ICT harus dikenal pasti di Malaysia. Kerangka Panduan ini akan terbina berdasarkan kepada budaya Malaysia yang mampu memacu kejayaan dan kompetensi sains di arena antarabangsa. Kerangka Panduan efektif yang bakal dibina boleh diguna pakai dalam mengaplikasikan PdPc sains. Maka, beberapa elemen telahpun dicadangkan untuk meningkatkan pencapaian SJK (T) melalui penggunaan ICT.
\end{abstract}

Kata kunci: ICT, PdPc Sains, murid-murid, guru-guru sains

(C) 2018 Penerbit UTM Press. All rights reserved

\subsection{PENGENALAN}

Perdana Menteri Malaysia, Datuk Seri Najib Tun Razak merangka hala tuju negara berdasarkan visi baharu yang dikenali sebagai Transformasi Nasional 2050 atau TN50. Matlamat utama TN 50 adalah bagi 'membentuk satu negara bangsa yang benar-benar berwibawa serta berminda par excellence' (BERNAMA, 2016). Unsur-unsur kreatif dan inovatif akan menjadi tunggak untuk menjamin kejayaan TN50 (The Star Online, 2016).

Asas kejayaan TN50 bergantung kepada ciri-ciri kreatif dan inovatif yang boleh diaplikasikan dengan meluas dalam pendidikan abad ke-21 dengan tujuan mencapai matlamat TN50 dengan jaya, tepat pada masanya. Jelas bahawa TN50 akan menjadi satu landasan baharu untuk para pengamal pendidikan memperkasakan bidang masing-masing dan terus bersaing di peringkat antarabangsa.

Dalam era TN50, pendidikan Sains menjadi satu bidang yang teramat penting dan keperluan literasi sains amat diutamakan. Kewujudan generasi muda yang kaya dengan budaya kreatif dan inovatif mampu menguasai sains dan menjadikannya sebagai landasan 
hidup. Selain TN50, Pendidikan 4.0 yang semakin popular di arena antarabangsa, mengutamakan pembelajaran perkara baharu dengan cara baharu (Fisk,2017). Perubahan Pendidikan 4.0 akan menjadi realiti dengan adanya kemajuan teknologi dan keupayaan dan kepantasan mengadaptasikan kemajuan teknologi tersebut. Tambahan pula, (Granito \& Chernobilsky, 2012) berpendapat budaya sains mampu dikembangkan dengan adanya teknologi yang menjadi satu alat bantuan pembelajaran yang berkuasa.

ICT telah diselitkan dalam pelbagai bidang demi memperkasakan martabat negara di arena antarabangsa. Pelbagai usaha dalam bentuk dasar-dasar baharu telah mengorak langkah ke arah menyelitkan ICT secara sepenuhnya dalam sistem pendidikan Negara. ICT telah menjadi satu wahana yang paling berharga dalam abad ke-21. Dalam usaha meningkatkan pencapaian dan minat murid terhadap sains, pembelajaran abad ke-21 berteraskan ledakan maklumat digital yang menjadi asas kejayaan sesebuah negara harus menjadi pegangan. Literasi Digital terdiri daripada tiga komponen utama, iaitu celik maklumat, celik kemahiran ICT, dan celik huruf media (Samual Kai, Wah Chu, Reynolds, Tavares \& Notari, 2016:22).

Mishra (2011) mengklasifikasikan ICT sebagai pengetahuan asas dalam pembelajaran abad ke-21. Hal ini menunjukkan pengetahuan ICT telah diselitkan ke dalam pengetahuan asas murid yang harus dikuasai sepenuhnya. Anjakan ketujuh PPPM pula mengesyorkan agar guru-guru memanfaatkan ICT bagi meningkatkan kualiti pembelajaran di Malaysia (KPM, 2013). Berdasarkan penelitian dan pemberatan ini, jelas bahawa industri ICT terbukti menjadi tulang belakang pembangunan sesebuah negara termasuk Malaysia (Abdul Ghani, 2014).

Kementerian Pendidikan Malaysia (2015) juga menjadikan kemahiran maklumat, media dan teknologi sebagai salah satu kemahiran yang diperlukan dalam pembelajaran abad ke-21. Namun, Kementerian Pendidikan Malaysia masih menganggap cabaran utama pembelajaran abad Ke-21 adalah keupayaan guru-guru mengaplikasikan dan mengadaptasikan pelbagai sumber teknologi serta maklumat bagi melaksanakan PdPc yang efektif dan berkualiti serta relevan dengan perkembangan semasa (KPM, 2015). Kajian UNESCO 2012 melaporkan bahawa penggunaan ICT tidak beranjak daripada sekadar penggunaan pemprosesan perkataan (KPM, 2013: E-21). Ada negaranegara yang telah mengambil pelbagai langkah proaktif untuk mengubah keadaan ini.

Negara-negara seperti Finland (Ministry of Education and Culture Finland, 2014) telah mempunyai road map tersendiri dan Kanada (Kanada, 2000) telah mempunyai frame work untuk P\&P Sains mereka demi memartabatkan lagi penguasaan sains di negara masing-masing. Tujuan road map dan frame work ini adalah untuk mempromosikan sains dan teknologi maklumat dalam proses penyelidikan yang berterusan. Walaupun Jabatan Teknologi Pendidikan telah menubuhkan Sekolah Bestari pada tahun 2005 di Malaysia, yang bermatlamat melestarikan ICT, namun pencapaian Sains tidak dapat ditingkatkan dan usaha road map atau frame work jarang sekali dibincang. Maka, pengkaji ingin meneroka elemen-elemen yang menjadi asas kepada satu Kerangka Panduan yang amat sesuai yang boleh diikuti oleh seluruh warga pendidik agar aspirasi negara untuk mencapai tahap par excellence dapat dikecapi.

\section{Sejarah Sekolah Jenis Kebangsaan (Tamil)}

Selepas kedatangan British, sistem pendidikan semakin berkembang di Tanah Melayu. Sekolah-sekolah vernakular ditubuhkan berdasarkan kepada Akta Buruh yang berkuat kuasa. Sekolah Tamil mempunyai ciri-ciri yang lebih mencerminkan etnik yang berbeza dalam kaum India. Setiap kaum menghantar anak-anak mereka untuk mendapatkan pendidikan di sekolah yang menggunakan bahasa ibunda masing-masing. British menetapkan penubuhan sekolah mengikut kawasan petempatan dan sekolah aliran Tamil ditempatkan di ladang-ladang getah. Tujuan utama pendidikan di sekolah-sekolah vernakular pada masa itu hanya untuk memberi pendidikan setakat pendidikan yang paling rendah dan tidak mementingkan perpaduan masyarakat.

Kepentingan sekolah vernakular diberi perhatian dalam Laporan Razak 1956. Laporan ini menekankan kepentingan bahasa ibunda. Menurut Akta Pendidikan 1996 (Akta 550), 'Sekolah Jenis Kebangsaan' ertinya sekolah rendah kerajaan atau sekolah rendah bantuan kerajaan yang menggunakan bahasa Cina atau Tamil sebagai bahasa pengantar utama (Malaysia Commissioner of Law Revision, 1996). Rasional penubuhan sekolah vernakular adalah supaya tidak wujud masalah perkauman (Zainudin, Mohd Zaki \& Nur Azza, 2015) dalam sesebuah negara yang mempunyai pelbagai bahasa ibunda dan cara hidup. Sekolah vernakular mula beroperasi tanpa adanya satu keseragaman yang jelas tentang sukatan pelajaran, garis panduan dan piawaian (Mohd Faizal, Alvinson Roland Demong, Sazeli \& Mazlini, 2015). Kini, taraf fizikal sekolah-sekolah Tamil mengalami perubahan yang menggalakkan, namun pencapaian prestasi akademik belum mencapai standard kualiti yang diperlukan. Tahap dan standard SJK (T) dijangka dapat dimantap dengan pengaplikasian ICT dalam PdPc. Keberkesanan ICT dapat dibuktikan dengan adanya kajian-kajian penggunaan ICT dalam PdPc Sains.

\subsection{PENDIDIKAN STEM DI MALAYSIA}

Pengukuhan Pendidikan STEM di Malaysia merupakan usaha KPM untuk meningkatkan sumber pakar dan tenaga mahir dalam bidang penyelidikan dan industri. Sehubungan penekanan Pendidikan STEM dalam PPPM, KPM giat berusaha untuk menarik lebih ramai murid menceburi bidang STEM di peringkat sekolah (KPM, 2016).

Pendidikan STEM adalah pendidikan yang berasaskan kepada konsep mendidik murid dalam empat bidang; Sains, Teknologi, Kejuruteraan dan Matematik dengan mengintegrasikan dan mengaplikasikannya dalam konteks dunia sebenar; pendidikan STEM amat penting dalam usaha melengkapkan murid demi menghadapi cabaran dan berdaya saing di peringkat global (KPM, 2016b).

Konsep STEM mula diperkenalkan pada tahun 2001 di Amerika Syarikat yang membawa maksud, 'kaedah P\&P tradisional diganti dengan lebih banyak kaedah inkuiri penemuan dan pendekatan berasaskan projek' (Breiner, Johnson, Harkness, \& Koehler, 2012). Muhammad Abdul (2016) pula mendefinisikan STEM sebagai 'mengadunkan pengintegrasian Sains, Teknologi, Kejuruteraan, dan Matematik dalam proses P\&P'. Pendidikan STEM sebagai model dan sistem yang diamalkan di negara-negara Barat terbukti dapat membantu pelajar-pelajar meminati bidang sains dan matematik dan menjadi asas kepada pelajar untuk menguasai bidang kejuruteraan sains dan teknologi (Razali, Halizah, Badaruddin \& Siti 2013).

Selaras dengan perkembangan pendidikan dunia, Malaysia juga tidak mahu ketinggalan dalam bidang Pendidikan STEM. Oleh itu pendidikan STEM turut diperkenalkan di Malaysia. Pendidikan STEM ini mula mendapat perhatian umum negara-negara membangun seperti Malaysia. Semua pihak perlu sedar yang pendidikan Sains sekolah rendah mempunyai peranan yang penting dalam melahirkan saintis-saintis 
pada masa depan (Gul \& Yesilyurt, 2015). Keperluan STEM ini adalah sejajar dengan permintaan dunia agar mengubah keadaan bilik darjah yang lama kepada yang lebih aktif (The Skop, 2015).

Kementerian memberi komitmen yang tinggi dalam menggalakkan STEM pada semua peringkat pendidikan. Kerangka Konseptual Pendidikan STEM dibina untuk menyediakan negara dengan bilangan graduan STEM yang berkelayakan dan mencukupi untuk memenuhi keperluan pekerjaan dan sumber manusia berinovatif bagi memacu ekonomi negara (Badan Pusat Statistik, 2014:58).

Kementerian mengambil inisiatif bagi menggalakkan pendidikan STEM dengan memperkenalkan Blended Learning Open Source for Science or Mathematics Studies (BLOSSOMS) iaitu pusat sumber bagi STEM, melaksanakan pendekatan pembelajaran secara praktikal dan kemahiran dalam pendidikan STEM dan menyediakan infrastruktur dan kemudahan pendidikan STEM (Badan Pusat Statistik, 2014:59)

BLOSSOMS merangkumi koleksi video untuk meningkatkan minat terhadap STEM. National Blue Ocean Strategy (NBOS) pula membolehkan pembelajaran STEM secara amali dengan kaedah penyediaan makmal dengan lebih murah dan pantas.

Pintar Foundation pula melancarkan Unit Pembelajaran Bergerak Pintar (PMLU) kedua bagi memperkasakan lagi pendidikan STEM di Malaysia. PMLU ini direka khas bagi sekolah rendah yang menyediakan ruang pembelajaran yang menyeronokkan dan bakal menjelajah ke sekolah-sekolah pintar di Semenanjung untuk tempoh dua tahun (Shazwan, 2017). Pelaksanaan PMLU menjadi satu pendekatan inklusif kepada murid-murid sekolah rendah dalam meminati bidang sains dan teknologi.

Inisiatif PMLU merupakan usaha membantu murid-murid di kawasan bandar dan luar bandar untuk memupuk budaya sains dalam diri mereka. PLMU ini mampu mencetus minat dan mendidik murid-murid dalam bidang (STEM). Maka boleh membuat kesimpulan bahawa, KPM begitu prihatin dan yakin bahawa pendedahan yang berterusan dalam bidang STEM sejak di sekolah rendah lagi bakal melahirkan generasi muda yang peka kepada keperluan dunia dan mampu menyumbang sumber tenaga yang berpotensi tinggi. Kelahiran modal insan yang berkemahiran, dinamik dan berpotensi ini akan bakal memperkasakan negara di persada dunia.

Sains yang menjadi sebahagian STEM dapat diajar dengan pelbagai pendektan dan kaedah. Namun, cara terbaik untuk mempelajari sains adalah melalui cara "hands-on" dengan melakukan eksperimen dan membuat kesimpulan (Thinaheswary, 2014). Pembelajaran Sains seumpama ini tidak dapat dipelajari dengan melakukan bacaan, pemahaman dan penghafalan semata-mata. Maka para pelajar harus digalakkan untuk melakukan projek -projek untuk memantapkan lagi pemahaman sains mereka.

Seiring dengan itu, penglibatan murid-murid SJK (T) dalam bidang inovasi dan kreatif semakin terkenal di mata dunia. Mereka mampu melakukan yang terbaik sehingga mampu bersaing di peringkat antarabangsa. Science Fair for Young Children (SFYC) telah mengorak langkah demi merealisasikan pemahaman pelajar berhubung sains dengan lebih mudah.

Salah sebuah sekolah SJK (T) yang mencapai kejayaan pada peringkat antarabangsa ini ialah SJK (T) Ramakrishna di Pulau Pinang. Menurut Puan Logeswari A/P Ganeson guru Sains di sekolah tersebut, (tele-perbualan pada 8 Mac 2017 pada 8.17 malam) mendapati bahawa mereka menggalakkan murid-murid untuk menggunakan google sebagai tapak pencarian maklumat. Ia adalah faktor perdana kejayaan mereka pada peringkat amtarabangsa. Murid senantiasa didedahkan kepada 'internet' dan 'YouTube' apabila sesuatu kajian sains dilakukan. Ini secara tidak langsung telah membuktikan ICT telah berperanan dalam situasi ini.

\subsection{ISU PENDIDIKAN SAINS MENGGUNAKAN ICT DI SJK (T)}

Bukan sekadar memperkenal TN50 sahaja, malah kerajaan yang begitu prihatin tentang kemajuan masyarakat terutamanya masyarakat India dalam bidang pendidikan. Justeru, kerajaan telah turut memperkenalkan Malaysian Indian Blueprint (MIB Cooperation, 2017). Dalam usaha merealisasikan pendidikan sebagai asas kepada sesebuah masyarakat, Plan Tindakan Sekolah Tamil (PTST) telah ditubuhkan oleh Jabatan Perdana Menteri untuk meningkatkan status SJK (T) di seluruh Malaysia. MIB yang dilancarkan pada 23 April 2017 mencadangkan empat langkah utama untuk meningkatkan status sekolah-sekolah Tamil di Malaysia seperti yang diperjelaskan dalam Jadual 1.

Jadual 1 Langkah-langkah Malaysian Indian Blueprint (MIB)

\begin{tabular}{|c|c|c|}
\hline Bil & Matlamat & Cara Pelaksanaan \\
\hline 1 & $\begin{array}{l}\text { Mengurangkan jurang kelulusan subjek UPSR antara } \\
\text { SJK (T) dengan SJK (C) dan SK dalam sepuluh tahun } \\
\text { yang akan datang. }\end{array}$ & $\begin{array}{l}\text { Kurikulum SJK (T) akan diselaraskan dengan Falsafah Pendidikan Negara, dan } \\
\text { Standard Pendidikan Antarabangsa. Guru -guru akan dilatih untuk mengajar dengan } \\
\text { lebih berkesan. }\end{array}$ \\
\hline 2 & $\begin{array}{l}\text { Standard minimum dicapai untuk prasarana, } \\
\text { pengurusan staf dan indikator kualiti yang lain dalam } \\
\text { sepuluh tahun yang akan datang. }\end{array}$ & $\begin{array}{l}\text { Semua sekolah Tamil mesti dilengkapi dengan kemudahan-kemudahan supaya } \\
\text { mewujudkan persekitaran pembelajaran yang kondusif dan memastikan kemudahan } \\
\text { asas lengkap (seperti makmal sains). Tambahan pula, plan tindakan ini mengutamakan } \\
\text { usaha membaik pulih dan menaik taraf kemudahan dengan cepat. }\end{array}$ \\
\hline 3 & $\begin{array}{l}\text { Meningkatkan tahap profesionalisme guru besar dan } \\
\text { guru-guru melalui pembangunan profesionalisme } \\
\text { secara sistematik. }\end{array}$ & $\begin{array}{l}\text { Melatih guru untuk mengajar secara efektif. } \\
\text { Meningkatkan pengajaran berasakan ICT Merancang dan melaksanakan } \\
\text { pembelajaran Higher Order Thinking Skills (HOTS). } \\
\text { Menyediakan kakitangan pemantauan dan sokongan yang mencukupi bagi memastikan } \\
\text { penyampaian kandungan yang berkualiti }\end{array}$ \\
\hline 4 & $\begin{array}{l}\text { Memastikan kemahiran bahasa meningkat dan } \\
\text { keperluan kelas peralihan dihapuskan dalam lima } \\
\text { tahun lagi (MIB cooperation, 2017). }\end{array}$ & $\begin{array}{l}\text { Kerajaan telah memperkenalkan kurikulum standard Bahasa Melayu pada peringkat } \\
\text { sekolah rendah dengan sokongan yang intensif untuk pelajar yang menghadapi } \\
\text { kesukaran belajar dalam Tahun } 4 \text { hingga } 6 \text {. }\end{array}$ \\
\hline
\end{tabular}

Selain MIB terdapat juga satu lagi dasar yang diperkenalkan di sekolah-sekolah vernakular pada tahun 2016 yang memberi satu landasan baharu dalam PdPc Sains di SJK (T). Dasar ini diberi nama sebagai Dual Language Program (DLP). Di sekolah-sekolah terpilih yang menjalankan DLP, murid-murid mula diajar dengan menggunakan bahasa Inggeris untuk mempelajari Sains (KPM, 2016a). Pada masa yang sama ada juga sekolah yang masih menggunakan bahasa Tamil untuk mempelajari Sains. 
Dalam era TN50, MIB dan DLP yang mengejar kemajuan dalam pendidikan, ketiadaan minat dalam mata pelajaran Sains menjadi satu isu yang sedang dihadapi oleh negara maju dan negara yang sedang membangun (Nazirah Mat Sin., Othman Talib., Putri Nazirah., 2013). Ketiadaan minat dalam bidang sains turut menjadi satu isu utama negara Malaysia. Menurut (Abu Bakar, 2017), nisbah pelajar sains kini ialah 21 peratus sahaja. Penglibatan ini jauh lebih rendah jika dibandingkan dengan matlamat kerajaan untuk mencapai peratusan 40:60. Keadaan ini perlu ditangani dengan kadar segera agar masa depan negara yang lebih bersifat kompetensi di arena antarabangsa dapat dicapai.

Kini, pencapaian pendidikan sains di SJK (T) dianggap berada pada kedudukan kritikal. Perhatian dan komitmen pelbagai pihak sewajarnya perlu diberikan untuk meningkatkan pencapaian sains murid India SJK (T) (Ong \& Shamalah, 2014). Perhatian dan inisiatif pelbagai pihak amat diperlukan kerana sekolah dan sistem pendidikan menjadi satu platform strategik dan kritikal untuk pembangunan bangsa (Sivapalan, Ong, Marsitah, Ong, Ong, dan Badariah, 2015).

\subsection{KAJIAN-KAJIAN PENGGUNAAN ICT DALAM PENGAJARAN DAN PEMUDAHCARAAN SAINS}

Pelajar yang gagal untuk mahir dalam ICT, dilihat sebagai individu yang 'ketinggalan zaman' yang mempunyai pengetahuan yang cetek dalam prestasi akademik (Mazalah, Jamaludin, Ahmad, Aidah, Fariza, Mohd Yusof \& Rosseni, 2016). ICT merangkumi ruang lingkup yang sangat luas. Pada umumnya ICT merupakan teknologi yang berdasarkan keperluan pemprosesan data. Secara khususnya ICT merupakan satu perisian untuk mengubah, menyimpan, memproses, melindungi, memindah dan mendapatkan maklumat tanpa mengira tempat dan waktu. Rentetan sejarah ICT di Malaysia telah bermula sejak tahun 1990 lagi.

Jadual 2 menunjukkan beberapa program pendidikan ICT yang dianggap penting dalam perjalanan dan perkembangan ICT di Malaysia

Jadual 2 Program-program ICT di Malaysia

\begin{tabular}{|c|l|c|}
\hline BIL & \multicolumn{1}{|c|}{ PROGRAM } & TAHUN \\
\hline 1 & Bahagian Teknologi Pendidikan (Pelan Strategik 2011-2015) & 1972 \\
\hline 2 & Projek Sekolah Bestari & 1998 \\
\hline 3 & Memperkenalkan Mata pelajaran Teknologi Maklumat untuk sekolah menengah & 1999 \\
\hline 4 & Pengajaran dan Pembelajaran Sains dan Matematik dalam Bahasa Inggeris (PPSMI) & 2003 \\
\hline 5 & Program Pembestarian Sekolah & 2006 \\
\hline 6 & Program 1 Bestari Net / Virtual Learning Environment VLE & 2012 \\
\hline 7 & PPPM & $2013-2025$ \\
\hline
\end{tabular}

Pelaksanaan teknologi dalam pendidikan bermula sejak awal 60-an di Eropah dan di Amerika Syarikat. Selaras dengan perkembangan dunia, Malaysia juga turut mengaplikasikan teknologi dalam pendidikan yang mengalami perubahan yang berterusan (Roslaili \& Wan Zamani, 2015).

Bahagian Teknologi Pendidikan (BTP) ditubuhkan pada 19 Jun 1972. BTP beroperasi berdasarkan 8 fungsi utamanya. Fungsi kedua BTP melibatkan 'perancangan dan penyelarasan inisiatif ICT serta memantau perkhidmatan sokongan ICT untuk P\&P'. Fungsi ketiganya pula bermatlamat merancang, menyelaras, melaksana, menilai dan memantau pembestarian sekolah.

ICT melalui sistem Frog VLE akan membantu memperkukuh proses PdPc di semua 10,000 buah sekolah di Malaysia. Murid terdedah kepada akses kandungan yang lebih luas, menarik, dan interaktif. Pilihan pembelajaran kendiri dan Pendidikan Jarak Jauh (PJJ) agak luas. ICT akan berperanan sebagai titi yang menghubungkan bandar dan luar bandar. Rangkaian Frog VLE berfungsi sebagai asas kepada pembinaan platform pembelajaran maya yang dapat digunakan oleh guru, murid, dan ibu bapa untuk berkongsi sumber pembelajaran, melaksanakan pembelajaran secara interaktif, dan berkomunikasi secara maya (KPM, 2013). Tambahan pula penggunaan ICT dikenal pasti sebagai langkah terbaik untuk menghadapi kerumitan mata pelajaran sains (Nazirah et al, 2013).

Chew, Lim \& Shuki Osman (2015), menjalankan kajian mengenai keperihatinan guru sains dan matematik sekolah rendah berhubung dengan Lesson Study. Pengkaji mendapati guru-guru mempunyai satu tahap kebimbangan yang tinggi tentang beberapa perkara lain, seperti tugas, aktiviti selain Lesson Study dan mereka mempunyai satu tahap kebimbangan yang rendah tentang akibat melaksanakan Lesson Study untuk pelajar masing-masing.

Ong \& Shamalah (2014), mengkaji tentang penguasaan kemahiran proses sains asas dalam kalangan murid India di beberapa buah sekolah rendah di Perak. Objektif kajian adalah untuk membandingkan tahap penguasaan Kemahiran Proses Sains Asas (KPSA) dalam kalangan murid India sekolah rendah tahap II berdasarkan jantina, lokasi sekolah dan aras tahun. Dapatan kajian menunjukkan tahap pencapaian murid India bandar lebih tinggi dan signifikan berbanding murid India luar bandar dalam KPSA secara keseluruhan.

Menurut Thinaheswary (2014) Science Fair for Young Children (SFYC) telah mengorak langkah agar murid-murid SJK (T) mampu bersaing di peringat antarabangsa. Kejayaan demi kejayaan dapat diraikan kerana adanya budaya 'hands on' dan budaya berdamping dengan ICT yakni bantuan daripada "YouTube" (Logeswari Ganeson, guru sains SJK (T) Ramkrishna, Pulau Pinang). Senario ini memberi gambaran bahawa budaya penggunaan ICT secara sepenuhnya membuahkan hasil yang baik di arena antarabangsa. Maka dengan itu pembudayaan ICT boleh dijadikan sebagai budaya di SJK (T). Berdasarkan kepada kejayaan-kejayaan dan kajian-kajian sebelum ini, maka jelas keperluan Kerangka Panduan pendidikan sains menggunakan ICT untuk SJK (T) amat penting.

Dunia bergerak pantas ke arah media digital, peranan ICT dalam pendidikan telah menjadi semakin penting. ICT telah mengubah cara bagaimana pengetahuan disebarkan dan cara guru berinteraksi dan berkomunikasi dengan para pelajar itu dan dan sebaliknya (Kavitha Kiran, 2014:25). Tambahan pula penggunaan ICT dikenal pasti sebagai langkah terbaik untuk menghadapi kerumitan mata pelajaran sains (Nazirah Mat Sin et al., 2013).

Kajian Noor Aini (2014) mendapati isi pengajaran data dapat disampaikan dengan lebih mudah menerusi penggunaan ICT Pengaplikasian ICT membolehkan pengajaran boleh digunakan secara berulang kali: boleh digunakan aktif walau di mana murid-murid berada. Kajian menunjukkan pengintegrasian ICT dalam pendidikan menyemai faktor perkembangan kanak-kanak secara lebih menyeluruh. 
Tambahan pula menurut Tuanku Badariah (2014:1) ICT berupaya meningkatkan kualiti pengajaran guru dan pengalaman murid. Selain itu penggunaan dan faedah ICT dalam P\&P sains sangat besar untuk guru dan pelajar sains.

Menurut Kavitha Kiran (2014:26) kekuatan komputer ialah keupayaannya memanipulasikan perkataan dan lambang atau simbol yang akan menjadi nadi utama sesuatu P\&P. Menurut Kavitha Kiran (2014:28) lagi, ICT boleh mempengaruhi cara bagaimana pelajar diajar, ia juga akan membolehkan pembangunan kemahiran-kemahiran kerjasama serta kemahiran-kemahiran penciptaan pengetahuan.

Salah satu faedah terpenting ICT dalam pengajaran adalah ICT boleh meningkatkan kualiti dan kuantiti peruntukan pendidikan Kavitha Kiran (2014:27). Sistem ICT di negara membangun berpotensi tinggi untuk menelan belanja kerana kos pemasangan lebih mahal.

Pengukuhan ICT perlu diperhebatkan menerusi kursus, menyediakan kemudahan komputer dan mengintegrasikan ICT dalam kurikulum (Noor ,2014:42). Mahmud (2012) berpendapat guru-guru dalam perkhidmatan celik ICT kerana pengalaman dan kursus yang diterima secara formal. Namun Kumutha \& Hamidah (2014) mencadangkan agar latihan-latihan yang mencukupi, motivasi serta galakan diberikan kepada guru supaya mereka diberi peluang untuk menggabungkan sumber ICT dalam P\&P di kelas.

Kajian (Ghavifekr, Ahmad, Muhammad \& Ng, 2014) yang melibatkan guru sekolah rendah mendapati, guru-guru perlu sentiasa bersedia secara menyeluruh dalam soal kecekapan ICT dan sikap positif memberi peluang untuk belajar pengetahuan kandungan berasaskan ICT.

Tuanku Badariah (2014) mendapati KPM telah melancarkan pelbagai strategi dan plan untuk mengesyorkan guru-guru menggunakan ICT dalam kelas. Namun penggunaannya masih tidak meluas. Pengintegrasian ICT dalam kelas bukan semudah yang disangkakan.

\subsection{KAJIAN-KAJIAN PENGGUNAAN TPACK DALAM PENGAJARAN DAN PEMUDAHCARAAN SAINS}

Menurut Sahin (2011), guru yang ingin berjaya dalam kerjaya mereka, mempunyai keperluan untuk memajukan diri mereka dalam pedagogi, teknologi, dan pengetahuan isi kandungan. Teknologi memainkan peranan penting untuk meningkatan pengetahuan guru dan menjadikan guru berada pada tahap terkini. Apabila guru menyatupadukan teknologi ke dalam pengajaran, pelajar lebih berminat untuk mempelajari subjek tersebut.

Kajian (Kafyulilo, Fisser, Peters \& Voogt, 2015) di Tanzania (melalui Program Pembangunan Profesional) terhadap guru pelatih sains, menunjukkan bahawa program pembangunan profesional berkesan dalam memajukan domain-domain berkaitan teknologi, tetapi bukan pengetahuan isi kandungan mereka dan pengetahuan pedagogi pengajaran, yang telah pun agak tinggi di permulaan kajian. Kajian ini juga menyimpulkan bahawa konsep kolaboratif antara guru-guru yang terbaik dalam sesuatu domain mampu membantu guru-guru yang kurang mahir dalam sesuatu domain dan sebaliknya.

Tambahan pula modul TPACK memberi satu input untuk guru-guru supaya mereka menilai semula kaedah pengajaran mereka dan berfikir kembali kesulitan yang dialami oleh pelajar dalam memahami sesuatu pengajaran (Meng \& Shuh, 2011).

Niess (2011), yang meneliti modul TPACK juga mendapati modul ini merupakan satu rangka kerja dinamik yang menggambarkan pengetahuan guru dalam usaha mereka bentuk, melaksana dan menilai kurikulum dan arahan ketika membimbing pelajar dengan teknologi digital.

\subsection{KERANGKA ICT DALAM PENDIDIKAN SAINS}

Negara-negara yang telah maju dari segi pendidikan telah mempunyai satu kerangka ICT untuk P\&P Sains negara masing-masing. Kerangka ICT ini telah mampu meningkatkan taraf negara tersebut di arena antarabangsa. Beberapa buah negara yang mempunyai taraf pendidikan dan pencapaian yang tinggi, mempunyai Kerangka Panduan untuk negara mereka.

Dengan mengenal pasti sifat sistem pelajaran berprestasi tinggi, (PISA, 2016) PISA membenarkan kerajaan dan pengajar mengenal pasti dasar berkesan yang mereka kemudiannya boleh menyesuaikan bagi konteks tempatan mereka.

Kerangka Panduan ICT yang sedia ada di negara-negara ini telah mengorak langkah ke arah pembanguan sains yang boleh dibanggakan. Berikut merupakan konsep ICT dalam P\&P sains di beberapa buah negara yang diperjelas melalui Jadual 3.

Jadual 3 Kerangka Panduan ICT

\begin{tabular}{|c|c|c|c|}
\hline Negara & Program & Pengendalian & $\begin{array}{l}\text { PISA } \\
2015\end{array}$ \\
\hline \multirow[t]{2}{*}{$\begin{array}{l}\text { FINLAND } \\
\text { (Ministry of Education and } \\
\text { Culture Finland, 2014) }\end{array}$} & $\begin{array}{l}\text { Information Society Programme } \\
2007-2015\end{array}$ & $\begin{array}{l}\text { Guru sepatutnya mempunyai kemahiran-kemahiran cemerlang } \\
\text { mengenai masyarakat, dan ICT sepatutnya menjadi sebahagian daripada } \\
\text { ajaran di semua tahap Pendidikan. } \\
\text { (pedagogi secara inovatif) }\end{array}$ & \multirow[b]{2}{*}{5} \\
\hline & $\begin{array}{l}\text { Open science and research road } \\
\text { map 2014-2017", }\end{array}$ & Mempromosikan sains dan ledakan informasi & \\
\hline Switzerland & $\begin{array}{l}\text { Kurikulum kebangsaan di } \\
\text { Switzerland dipanggil "Lehrplan } \\
\text { 21." }\end{array}$ & $\begin{array}{l}\text { Bermatlamat melahirkan individu-individu yang berazam tinggi, kreatif, } \\
\text { matang, serta berkelakuan baik dalam masyarakat. }\end{array}$ & 18 \\
\hline Amerika Syarikat & $\begin{array}{l}\text { National Education Technology } \\
\text { Plan [NETP] } 2010 .\end{array}$ & $\begin{array}{l}\text { Melahirkan gerenasi muda yang boleh berfikiran kreatif dan inovatif } \\
\text { berdasarkan teknologi. }\end{array}$ & 25 \\
\hline
\end{tabular}




\subsection{CADANGAN KERANGKA PANDUAN PENDIDIKAN SAINS BERASASKAN ICT di SJK (T)}

Berdasarkan kepada kajian-kajian ini jelas bahawa, Malaysia juga memerlukan satu Kerangka Panduan Sains yang berasaskan ICT yang sesuai untuk SJK (T) meningkatkan pencapaian murid dalam mata pelajaran Sains selaras dengan matlamat kerajaan Malaysia yang tertera dalam (MIB, 2017). Kerangka Panduan ini penting untuk memastikan aspirasi TN50 tercapai pada tahap par excellence (BERNAMA, 2016).

Selain itu, kerangka ini mampu memartabatkan sekolah-sekolah SJK (T) di peringkat kebangsaan yang akan meletakkan SJK (T) selaras dengan SK dan SJK(C) dengan mengurangkan jurang kelulusan subjek Sains UPSR. Kerangka Panduan selaku wahana yang paling berharga ini mampu menjadi satu komponen yang komprehesif untuk memartabatkan kedudukan sekolah SJK (T) di Malaysia. Dengan itu, Kerangka Panduan PdPc Sains berasaskan ICT dicadangkan melibatkan elemen-elemen yang menjurus kepada amalan guru, amalan TPACK dan amalan motivasi pelajar.

\section{i) Amalan Guru}

Profesion perguruan memerlukan guru-guru memperoleh kemahiran ICT untuk pelbagai tujuan seperti mencari, meneroka dan mendapat maklumat untuk kepentingan proses PdPc dalam bilik darjah (Mazalah, Jamaludin, Ahmad, Aidah, Fariza, Mohd, Rosseni dan Diana, 2016). Dalam usaha untuk mencapai satu ajaran komprehensif dengan menggunakan ICT, guru perlu yakin akan kepentingan dan manfaat penggunaan ICT dalam PdPc. Penggunaan ICT dalam PdPc telah mengubah keseluruhan konsep pendidikan dan telah terbukti membawa manfaat besar-besaran untuk kedua-dua guru dan pelajar (Kler, 2014: Granito \& Chernobilsky, 2012).

Dewasa ini pelbagai kekangan dihadapi oleh para guru dalam melaksanakan pengajaran ICT dalam kelas. Kemahiran mengoperasi komputer menjadi satu kekangan utama dalam kalangan guru. Para guru yang tidak cekap mengendalikan komputer, mempunyai keyakinan yang rendah untuk menggunakan komputer dalam kelas dan sebaliknya (Gilakjani, 2013). Kekurangan sokongan teknikal mengecewakan guru dan menyebabkan guru tidak menyepadukan teknologi komputer dalam bilik-bilik darjah mereka. Pengendalian perisian ' $h a r d w a r e$ ' and 'software' menyebabkan guru-guru menghadapi banyak masalah dan tidak mahu menggunakannya dalam kelas (Gilakjani, 2013).

Kekurangan latihan menjadi satu faktor utama PdPc jarang mengintergrasikan ICT dalam kelas. Sesungguhnya, guru seharusnya diberi latihan yang mencukupi untuk menggunakan peralatan ICT dengan berkesan dan cekap. Guru yang telah menghadiri kursus latihan dalam bahasa Inggeris dan ICT, lebih efisien, berkebolehan menggunakan komputer dan bersedia untuk melaksanakan ajaran Sains dalam bahasa Inggeris berbanding dengan guru yang tidak mempunyai latihan (Azidah, Ismail, Robitah \& Kumutha, 2011).

Manakala sikap guru amat mempengaruhi penggunaan ICT dalam kelas. Jika guru berfikiran positif terhadap ICT, maka wujudlah kesan positif dan pengintegrasian ICT dalam kelas dan sebaliknya (Kler, 2014: Gilakjani, 2013). Hasil kajian Fatin, Salleh, Bilal \& Salmiza (2014) mendapati penggunaan pelbagai bentuk ICT dalam PdPc dilaksanakan dalam pendidikan Sains di negara ini. Pada peringkat perlaksanaan, tahap kesesuaian penggunaan ICT, khususnya dalam pendidikan Sains amat bergantung kepada kelengkapan infrastruktur untuk perlaksanaan PdPc berbantukan ICT, daya kreativiti dan inovasi guru dan staf sokongan teknikal, kesediaan dan minat guru dan pelajar untuk melaksanakan P\&P berbantukan ICT, pengurusan pihak pengurusan sekolah berbantukan ICT (Fatin et al, 2014:69). Kajian mendapati bahawa tahap minat, kesediaan dan keupayaan guru sains dalam menggunakan ICT dalam PdPc adalah positif.

(Donnelly, McGarr \& O'Reilly, 2011) mengenalpasti tiga komponen utama sebagai kekangan pengintergerasian ICT dalam kelas. Ketiga-tiga kekangan tersebut melibatkan sumber, guru dan kandungan. Kekangan guru melibatkan peranan guru, kaedah pengajaran, organisasi gaya pengurusan, jenis-jenis penilaian, pengetahuan dan amalan, kesedaran sosial, dan kemahiran teknologi. Menurut Ghavifekr et al. (2016:39) walaupun KPM telah memulakan projek "1Bestarinet" sebagai platform pembelajaran maya yang berorientasikan ICT, namun kebanyakan sekolah dalam negara belum menerima budaya itu sepenuhnya dalam proses pengajaran dan pembelajaran.

Guru-guru yang berorientasikan peperiksaan semata-mata sudah pasti akan melemahkan minat dan motivasi murid-murid terhadap mata pelajaran sains (Meng et al, 2015). Dapatan kajiannya menunjukkan, pendidikan berkualiti lahir daripada tiga faktor iaitu pengetahuan isi kandungan guru, pengetahuan pedagogi guru dan pengalaman guru. Guru-guru menggunakan khidmat komputer untuk membuat rancangan mengajar, pembentangan power point untuk pembelajaran interaktif (Hoque et al, 2012). Keputusan mencadangkan bahawa guru mempamerkan tahap kepuasan tinggi ke arah kursus-kursus ICT kerana latihan menyumbang kepada pembangunan kemahiran mengajar mereka sendiri (Sánchez-garcía, Marcos \& Guanlin, 2013). Mereka juga mencadangkan penggunaan efektif ICT akan bergantung kepada panduan dan latihan dan kerjasama rakan sebaya. Garba et al, (2015) mengesyorkan agar menyediakan infrastruktur ICT yang asas dan mengalakan guru untuk menggunakan kemudahan itu dalam pengajaran dan pembelajaran.

Oleh kerana pelajar bertindak balas secara positif kepada ICT dan dimotivasikan oleh ICT, maka guru perlu berusaha untuk mewujudkan aktiviti pengajaran yang merangkumi beberapa bentuk alat ICT. Penyelidik menyimpulkan teknologi itu berpotensi menjadi satu alat bantuan pembelajaran efektif dan berkuasa yang mempunyai kepentingan tersendiri (Granito \& Chernobilsky, 2012:20).

Maka sumbangan guru akan menjadi satu elemen utama dalam Kerangka Panduan yang bakal dibina. Elemen guru berperanan dalam memartabatkan modal insan yang bakal dilahirkan mempunyai keperibadian mulia berasaskan acuan negara Malaysia serta mampu bersaing di persada dunia.

\section{ii) Amalan Technological Pedagogical Content Knowledge (TPACK)}

Menurut Mishra \& Koehler (2006) dalam menyampaikan pendidikan berkualiti, tiga komponen utama akan memainkan peranan iaitu isi kandungan, pedagogi dan teknologi serta hubungan di antara ketiga-tiga komponen ini. Gabungan kesemua elemen ini digelar sebagai TPACK. Modul TPACK memberi sumbangan utama dan unggul yang merangkumi profesion perguruan dan pembangunan guru. Tambahan pula TPACK memberi jenis pengetahuan yang diperlukan oleh seseorang guru untuk menyatupadukan teknologi yang berkesan (Koehler, Mishra, Kereluik, Tae \& Graham, 2014).

TPACK memberi satu input baharu bahawa ada teknik yang boleh diguna pakai untuk meningkatkan pencapaian pelajar dengan menjadikan PdPc lebih bermakna dan menarik. Konsep TPACK memberi input bahawa guru-guru perlu melihat satu situasi dalam pandangan yang berbeza. Pandangan itu melibatkan pengetahuan isi kandungan, pengetahuan pedagogi dan pengetahuan teknologi yang diintegrasikan dalam P\&P di kelas (Meng \& Shuh, 2011:97). 
Berdasarkan huraian ini jelas bahawa, modul TPACK boleh diintegrasikan sebagai salah satu elemen penting dalam Kerangka Panduan yang bakal dibina. TPACK menjadi modul yang mengaitkan teknologi dan pendidikan dengan pembangunan profesionalisme perguruan. Modul ini pada asalnya diambil daripada Shulman (1986) yang menggabungkan pedagogi dan pengetahuan isi kandungan. Berdasarkan teori itu, TPACK direka dengan menggabungkan teknologi sebagai lanjutan kepada teori yang dikemukakan oleh Shulman (Mishra \& Koehler, 2006). Modul TPACK ini menekankan hubungan saling mempengaruhi antara tiga domain pengetahuan iaitu pengetahuan isi kandungan, pengetahuan pedagogi dan pengetahuan teknologi serta gabungan antaranya. Menurut (Mishra \& Koehler, 2006) pengetahuan isi kandungan dan pengetahuan pedagogi sahaja belum mampu untuk merangkumi pengetahuan guru yang cemerlang.

Berikut merupakan modul TPACK yang direka oleh Mishra \& Koehler, 2006. Rajah 1 di bawah menunjukkan modul TPACK.

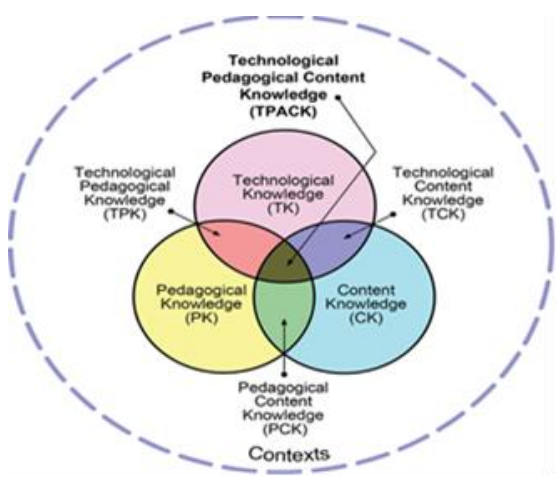

Rajah 1 Model TPACK

Menurut Mishra \& Koehler (2006) dalam menyampaikan pendidikan berkualiti, tiga komponen utama akan memainkan peranan iaitu isi kandungan, pedagogi dan teknologi serta hubungan di antara ketiga-tiga komponen ini membawa kepada TPACK.Tujuh komponen utama TPACK adalah seperti yang diterangkan melalui Jadual 4

Jadual 4 Komponen Utama TPACK

\begin{tabular}{|c|c|c|c|}
\hline $\mathrm{BIL}$ & KOMPONEN & PENERANGAN & KONSEP \\
\hline 1 & TK & $\begin{array}{l}\text { technological knowledge } \\
\text { pengetahuan teknologi }\end{array}$ & $\begin{array}{l}\text { pengetahuan dan penggunaan teknologi terkini dan pelbagai seperti komputer, } \\
\text { Internet, video digital, dan IWB. }\end{array}$ \\
\hline 2 & CK & $\begin{array}{l}\text { content knowledge / pengetahuan isi } \\
\text { kandungan }\end{array}$ & $\begin{array}{l}\text { pengetahuan konsep, fakta-fakta teori-teori, idea, rangka-rangka organisasi, } \\
\text { prinsip-prinsip, bukti, serta amalan mantap disiplin ilmu tertentu. }\end{array}$ \\
\hline 3 & PK & $\begin{array}{l}\text { pedagogical knowledge pengetahuan } \\
\text { pedagogi }\end{array}$ & $\begin{array}{l}\text { kefahaman mendalam tentang proses dan amalan } \mathrm{P} \& \mathrm{P} \text {, merangkumi tujuan } \\
\text { pendidikan, matlamat, nilai, dan strategi. }\end{array}$ \\
\hline 4 & PCK & $\begin{array}{l}\text { pedagogical content knowledgel } \\
\text { pengetahuan isi kandungan dan } \\
\text { pedagogi }\end{array}$ & $\begin{array}{l}\text { pengetahuan pedagogi yang boleh digunakan bagi ajaran isi kandungan } \\
\text { (persilangan dan interaksi pedagogi dan kefahaman isi). }\end{array}$ \\
\hline 5 & TCK & $\begin{array}{l}\text { technological content knowledge / } \\
\text { pengetahuan isi kandungan dan } \\
\text { teknologi }\end{array}$ & $\begin{array}{l}\text { pengetahuan bagaimana teknologi IWB boleh mewujudkan gambaran baru untuk } \\
\text { kandungan tertentu. }\end{array}$ \\
\hline 6 & TPK & $\begin{array}{l}\text { technological pedagogical knowledge / } \\
\text { pengetahuan teknologi pedagogi }\end{array}$ & $\begin{array}{l}\begin{array}{l}\text { satu persefahaman bagaimana } \mathrm{P} \& \mathrm{P} \text { berubah apabila teknologi tertentu } \\
\text { digunakan. }\end{array} \\
\end{array}$ \\
\hline 7 & TPACK & $\begin{array}{l}\text { Technological Pedagogical Content } \\
\text { Knowledge } \\
\text { kandungan, pedagogi dan teknologi }\end{array}$ & $\begin{array}{l}\text { merujuk kepada pengetahuan bagaimana untuk menyepadukan ajaran isi } \\
\text { kandungan, teknologi dan pedagogi. }\end{array}$ \\
\hline
\end{tabular}

Berdasarkan modul asas ini, terdapat tiga bidang utama sebagai satu komponen atau berasingan. Daripada tiga bidang ini, ia berkembang dengan bercantum dengan satu komponen yang lain. Gabungan ini melibatkan tiga komponen lagi. Akhir sekali TPACK terbentuk dengan adanya gabungan kesemua bidang ini. TPACK telah diadaptasi dan digunakan di negara-negara seperti Kuwait, Greece, Taiwan, Hong Kong, Singapura dan Afrika (Kafyulilo et al, 2015). Sahin (2011) dan Campbell \& Campbell (2015) mengesahkan TPACK sebagai satu tinjauan yang mempunyai kesahan dan kebolehpercayaan yang tinggi untuk PdPc.

Kajian Kafyulilo et al (2015) menyimpulkan bahawa konsep kolaboratif antara guru-guru yang terbaik dalam sesuatu domain mampu membantu guru-guru yang kurang mahir dalam sesuatu domain dan sebaliknya. Tambahan pula amalan TPACK, mampu menyatupadukan teknologi guru pelatih dan penggunaan teknologi ditingkatkan untuk bilik-bilik darjah mereka sendiri. Guru-guru kini tidak diajar dengan menggunakan teknologi (semasa mereka berada di bangku sekolah) dan mereka juga tidak biasa menggunakan ICT semasa usia muda mereka. Guru-guru yang berlatarbelakangkan situasi seumpama ini terpaksa merangka P\&P mereka berasaskan teknologi kini (Niess, 2011).

Mishra \& Koehler (2006:1046) percaya bahawa modul rangka kerja TPACK boleh membimbing perkembangan kurikulum dalam bidang pendidikan guru yang berkaitan dengan teknologi. Dapatan kajian Jang \& Tsai (2012) menunjukkan guru-guru yang berpengalaman mengaplikasikan TPACK dengan lebih luas berbanding guru-guru baharu. Hal ini secara tidak langsung membawa maksud bahawa guruguru yang berpengalaman mempercayai yang TPACK akan menjadi teknik terbaik untuk P\&P di kelas. 
TPACK memberi satu input baharu bahawa ada teknik yang boleh diguna pakai untuk meningkatkan pencapaian pelajar dengan menjadikan P\&P lebih bermakna dan menarik. Konsep TPACK memberi input bahawa guru-guru perlu melihat satu situasi dalam pandangan yang berbeza. Pandangan itu melibatkan pengetahuan isi kandungan, pengetahuan pedagogi dan pengetahuan teknologi yang diintegrasikan dalam P\&P di kelas (Tee \& Lee, 2011:97).

Modul TPACK memberi satu input untuk guru-guru supaya mereka menilai semula kaedah pengajaran mereka dan berfikir kembali kesulitan yang dialami oleh pelajar dalam memahami sesuatu pengajaran (Tee \& Lee, 2011).

Garba et al, (2015:78) mencadangkan agar guru yang mengikuti latihan perguruan diintegrasi dengan ICT dan diarahkan agar membina kemahiran guru dan kecekapan menggunakan teknologi TPACK dalam amalan pengajaran.

iii)

$$
\text { Motivasi pelajar }
$$

Proses pengajaran yang berbentuk formal dan tidak formal, tidak akan mencapai tahap optimum jika individu yang bergelar pelajar tidak menunjukkan motivasi diri yang tinggi untuk menuntut ilmu pengetahuan serta kemahiran daripada guru (Suhaimi, 2014). Maka motivasi memainkan peranan yang amat penting dalam proses pembelajaran. Tinjauan kajian yang berkaitan dengan motivasi pelajar menunjukkan bahawa kebanyakan penyelidik Suhaimi (2014) dan Barger \& Byrd (2011) mendapati, aspek pengajaran guru yang berkualiti akan membantu meningkatkan motivasi yang tinggi dan menjadi pemangkin kepada keupayaan pelajar itu untuk melaksanakan pembelajaran dengan berkesan.

ICT mempunyai peranan yang amat penting bagi meningkatkan motivasi pelajar dalam proses PdPc. Peralatan teknologi banyak mempengaruhi motivasi pelajar dan akan membawa kepada perubahan yang baik. Generasi abad ke-21 yang begitu rutin dan menjadi pengguna asli dunia teknologi dan digital akan memahami penggunaannya dengan lebih mudah. Dalam situasi seumpama ini peralatan teknologi akan banyak mempengaruhi motivasi pelajar dalam aktiviti P\&P (Granito \& Chernobilsky, 2012). Motivasi murid banyak bergantung kepada elemen-elemen guru dan juga ICT yang menyumbang kepada peningkatan tahap motivasi murid. ICT yang kian berkembang pesat telah menjadi salah satu faktor penarik dalam meningkatkan motivasi para pelajar (Granito \& Chernobilsky, 2012) dan (Meisalo, Lavonen, Sormunen, Vesisenaho \& Education, 2010). Menurut Azidah et al, (2011) ICT telah meningkatkan motivasi untuk belajar dengan lebih berkesan dan berkualiti. Fook \& Gurnam (2013), Ciampa (2014) dan Granito \& Chernobilsky (2012) mendapati ICT berkeupayaan untuk memudahkan persembahan pengajaran, mempelbagaikan aktiviti pengajaran serta menjadikan sesi pembelajaran lebih seronok dan menarik kepada pelajar. Tambahan pula Chua \& Don (2013) mendapati mod pengujian yang berasaskan komputer telah menarik motivasi responden untuk menyertai kajian. ICT membantu untuk memotivasikan pelajar dan pada masa yang sama meningkatkan prestasi pelajar (Sánchez-garcía et al, 2013). Keperluan setiap pelajar berbeza. ICT memenuhi keperluan individu pelajar dan juga membantu mereka dalam pengajian mereka dengan mendorong mereka belajar. Dengan ini para pelajar belajar dengan cara yang lebih berkesan (Kler, 2014).

Penggunaan komputer dan peralatan mudah alih menjadi wahana baru dan merupakan satu budaya P\&P yang agak baru dalam media instruksional di kelas (Nikou \& Economides, 2014). Hal ini sedemikian kerana teknologi komputer dan peralatan mudah alih boleh memudahkan pembelajaran "bila-bila masa dan di mana-mana" (Nikou \& Economides, 2014). Keupayaannya yang boleh mendidik di manamana sahaja menyebabkan media ini semakin popular. Secara tidak langsung keunikan ini telah meningkatkan motivasi dalaman, motivasi luaran dan kecekapan diri pelajar (Castillo-Merino \& Serradell-López, 2014) dan (Ciampa, 2014). Media baru dan kontemporari ini juga telah meningkatkan motivasi pelajar yang sederhana dan lemah untuk mempelajari Sains.

Tahap motivasi pelajar berubah dan memberi kesan berdasarkan kepada beberapa faktor. Apabila keperluan psikologi pelajar dipenuhi, maka tahap motivasi mereka belajar dengan menggunakan ciri-ciri PdPc pembelajaran abad ke-21 yang berasaskan peralatan mudah alih meningkat. Apabila autonomi pelajar dan peraturan diri disokong dan terdapat satu pengaruh sosial positif, pelajar-pelajar berasa lebih bermotivasi. Penambahan pelbagai peralatan mudah alih yang meluas dan dapat diperoleh dengan kos rendah serta penggunaan khidmat internet tanpa talian menjadi pemacu utama pendidikan era baru ini (Nikou \& Economides, 2014). Situasi seperti ujian yang sukar juga menjadi salah satu faktor yang menjurus ke arah kehilangan motivasi (Timmers, Braber-Van Den Broek \& Van Den Berg, 2013).

Tambahan pula, pelajar-pelajar yang mempunyai motivasi dalaman yang tinggi menunjukkan kesungguhan untuk belajar dan memahami sesuatu perkara. Penggunaan teknologi mudah alih juga membuka ruang untuk individu untuk mengamalkan budaya bekerjasama. Teknologi mudah alih boleh menjadi satu alat menyampaikan arahan perkhidmatan sebagai satu medium untuk bekerjasama. Pelajar-pelajar boleh belajar dengan cara mereka sendiri, berganding bahu dengan lain dan menawarkan nasihat kepada satu sama lain melalui pelbagai aplikasi (Ciampa, 2014).

Berdasarkan ketiga-tiga elemen ini boleh dibuat kesimpulan bahawa letiga-tiga elemen ini boleh dijadikan sebagai elemen yang efektif dalam pembinaan Kerangka Panduan Pendidikan sains di SJK (T).

Elemen-elemen seperti dalam Rajah 2 berikut boleh dijadikan asas kejayaan Kerangka Panduan di negara Malaysia. 


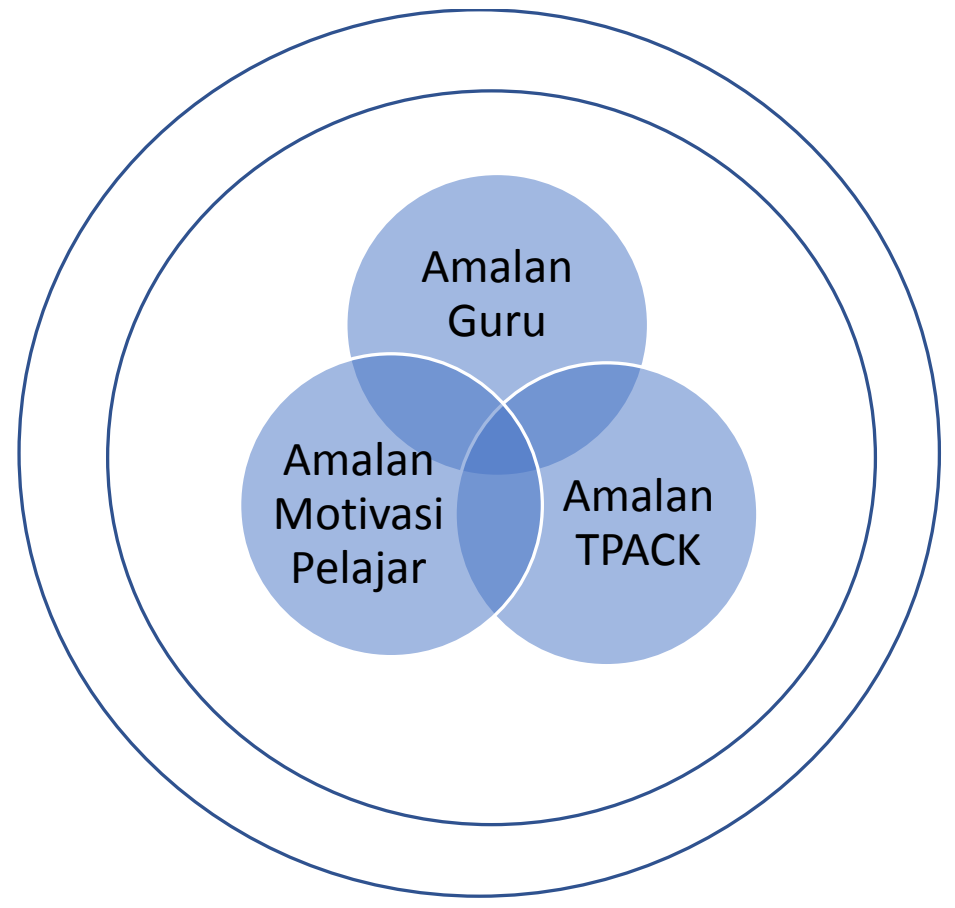

Rajah 2 Kerangka Panduan PdPc Efektif Sains Berasaskan ICT

\subsection{KESIMPULAN}

Terdapat keperluan membina satu Kerangka Panduan pendidikan Sains menggunakan ICT di SJK (T). Kewujudan Kerangka Panduan ini akan menjadi satu pedoman untuk PdPc Sains menggunakan ICT berjalan dengan lebih lancar di sekolah SJK (T) yang dapat meningkatkan pencapaian murid dalam mata pelajaran Sains. Kerangka ini juga dapat menarik minat serta motivasi pelajar SJK (T) untuk melibatkan diri dengan lebih aktif dalam PdPc Sains di kelas.

Kerangka ini dapat meningkatkan penglibatan guru yang lebih aktif dalam amalan ICT dan dalam mata pelajaran Sains dan seterusnya meletakkan negara Malaysia duduk sama tinggi dengan negara-negara maju ke arah merealisasikan aspirasi TN50. Pada masa yang sama, kerangka ini juga dapat menarik minat para murid untuk belajar subjek Sains. Murid-murid juga akan berpeluang untuk menjalankan kajian saintifik berasaskan ICT.

Harapan daripada Kerangka Panduan ini adalah agar pendidikan Sains berdasarkan rangka kerja ini akan memotivasi dan mendorong guru-guru di samping menarik minat pembelajaran murid-murid terhadap mata pelajaran Sains. Selain itu, kerangka panduan ini berkeupayaan mendidik murid-murid sekolah rendah dalam mata pelajaran Sains dan seterusnya melahirkan individu yang berketerampilan dalam bidang Sains pada masa akan datang.

Kerangka Panduan ini boleh digunakan sebagai batu loncatan yang akan memperkenalkan satu sumber yang berasaskan ICT (iaitu TPACK) di SJK (T). Adalah diharapkan, Kerangka ini dapat menjana satu anjakan paradigma dalam amalan PdPc Sains guru yang dapat memotivasikan minat murid-murid terhadap pembelajaran Sains yang berasaskan ICT.

\section{Rujukan}

Abu Bakar. (2017). Kekurangan Minat dalam Aliran Sains.siaran radio. Minnal.

Adam, B.\& Kirstin, B. (2011). Motivation and Computer-Based Instructional Design. Journal of Cross-Disciplinary Perspectives in Education, 4(1), 1-9.

Anuar, R., Zamani, W., \& Zakaria, W. (2015). TPACK dalam Pendidikan Seni Visual: Satu Kajian Mengenai Kesediaan Pelajar Menggunakan E- Pembelajaran dalam Pembelajaran Pendidikan Seni Visual. Jurnal Seni Dan Pendidikan Seni, 3, 8-18.

Ayoub Kafyulilo., Petra Fisser., Jules Peters., Jike Voogt. (2015) ICT Use In Science And Mathematics Teacher Education In Tanzania: Developing Technological Pedagogical Content Knowledge. Australasian Journal of Educational Technology, 31(4), 381-399.

Azidah Abu Ziden, Ismail, I., Robitah Spian, \& K. Kumutha. (2011). The Effects of ICT Use in Teaching and Learning on Students' Achievement in Science Subject in a Primary School in Malaysia. Malaysia Journal of Distance Education, 13(2), 19-32. https://doi.org/10.7575/aiac.ijels.v.3n.2p.25

Campbell, C., \& Campbell, C. (2015). Evaluation of the Learning Designs of Cloud- based Content Using the TPACK Framework Using the TPACK Framework, (JUNE).

Castillo-Merino, D., \& Serradell-López, E. (2014). An Analysis Of The Determinants Of Students' Performance In E-Learning. Computers in Human Behavior, 30 , 476-484. https://doi.org/10.1016/j.chb.2013.06.020

Chew, C.M., Lim, C.S., \& Shuki Osman (2015). Primary School Mathematics and Science Teachers Stages of Concern About. Asia Pacific Journal of Educators and Education, 30, 1-14.

Chua, Y. P., \& Don, Z. M. (2013). Effects Of Computer-Based Educational Achievement Test On Test Performance And Test Takers' Motivation. Computers in Human Behavior, 29(5), 1889-1895. https://doi.org/10.1016/j.chb.2013.03.008

Ciampa, K. (2014). Learning In A Mobile Age: An Investigation Of Student Motivation. Journal of Computer Assisted Learning, 30(1), 82-96. https://doi.org/10.1111/jcal.12036 
Donnelly, D., McGarr, O., \& O’Reilly, J. (2011). A Framework For Teachers' Integration Of ICT Into Their Classroom Practice. Computers and Education, 57(2), 1469-1483. https://doi.org/10.1016/j.compedu.2011.02.014

Fatin, A., Salleh, A.; M., Bilal, A. M., \& Salmiza, S. (2014). Faktor penyumbang Kepada Kemerosotan Penyertaan Pelajar Dalam Aliran Sains: Satu Analisis Sorotan Tesis. Sains Humanika, 2(4), 63-71. https://doi.org/10.14221/ajte.2011v36n3.2

Fook, C. Y., \& Gurnam, K. S. (2013). Peranan Teknologi Maklumat Terhadap Peningkatan Motivasi Pembelajaran di Kalangan Pelajar Universiti. Journal of Chemical Information and Modeling, 53(9), 1689-1699. https://doi.org/10.1017/CBO9781107415324.004

Garba, S. A., Byabazaire, Y., \& Busthami, A. H. (2015). Toward The Use Of 21st Century Teaching-Learning Approaches: The Trend Of Development In Malaysian Schools Within The Context Of Asia Pacific. International Journal of Emerging Technologies in Learning, 10(4), 72-79. https://doi.org/10.3991/ijet.v10i4.4717

Ghavifekr, S., Kunjappan, T., Ramasamy, L., \& Anthony, A. (2016). Teaching and Learning with ICT Tools: Issues and Challenges from Teachers' Perceptions. Malaysian Online Journal of Educational Technology, 4(2), 38-57. Retrieved from http://www.mycite.my/en/article/articlesby/author/63189http://bit.ly/2fRI88H

Gilakjani, A. P. (2013). Factors Contributing To Teachers' Use Of Computer Technology In The Classroom. Universal Journal of Educational Research, 1(3), 262267. https://doi.org/10.13189/ujer.2013.010317

Granito, M., \& Chernobilsky, E. (2012). The Effect of Technology on a Student Motivation and Knowledge Retention. NERA Conference Proceedings 2012, 17. Retrieved from http://digitalcommons.uconn.edu/nera_2012/17\%5CnThis

Hoque, K. E., Ahmad Zabidi Abdul Razak, \& Zohora, M. F. (2012). ICT Utilization among School Teachers and Principals in Malaysia. International Journal of Academic Research in Progressive Education and Development, 1(4), 17-34.

Ismail Sahin. (2011). Development of Survey of Technological Pedagogical and Content Knowledge (TPACK). Turkish Online Journal of Educational Technology TOJET, 10(1), 97-105.

Jang, S. J., \& Tsai, M. F. (2012). Exploring The TPACK Of Taiwanese Elementary Mathematics And Science Teachers With Respect To Use Of Interactive Whiteboards. Computers and Education, 59(2), 327-338. https://doi.org/10.1016/j.compedu.2012.02.003

Jonathan Breiner., Corla Johnson., Shelly Sheots Harkness., \& Catherine M. Koehler. (2012). What is STEM? A Discussion About Conceptions of STEM in Education and Partnerships. School Science and Mathematics, 112, 3-11. https://doi.org/10.1111/j.1949-8594.2011.00109.

Kafyulilo, A., Fisser, P., \& Pieters, J. (2015). ICT Use In Science And Mathematics Teacher Education In Tanzania: Developing Technological Pedagogical Content Knowledge. Australasian Journal of Educational Technology, 31(4), 381-399.

Kanada. (2000). A Framework for Science and Technology Advice : Principles and Guidelines for the Effective Use of Science and Technology Advice in Government Decision Making, 1-22. Kanada. Retrieved from http://publications.gc.ca/collections/Collection/C2-500-2000E.pdf.

Kler, S. (2014). ICT Integration in Teaching and Learning: Empowerment of Education with Technology. Issues and Ideas in Education, 2(2), 255-271. https://doi.org/10.15415/iie.2014.22019

Koehler, M. J., Mishra, P., Kereluik, K., Shin, T. S., \& Graham, C. R. (2014). The Technological Pedagogical Content Knowledge Framework. Educational Communication and Technology, 101-111. https://doi.org/10.1007/978-1-4614-3185-5.

KPM (2013). PPPM_lengkap. Retrieved from http://www.moe.gov.my/images/dasar- kpm/PPP/articlefile_file_003107.pdf.

KPM. (2016a). Garis Panduan Dual Language Programme(DLP) $\quad$ (Vol. $\quad 0)$ Retrieved from http://jpnmelaka.moe.gov.my/v3/images/destop/Garis_panduan_DLP_Versi_1.0_2015.pdf.

KPM. (2016b). Panduan Pelaksanaan STEM dalam Pengajaran dan Pembelajaran. In Bahagian Pembangunan Kurikulum (p. 69). Retrieved from https://cms.mrsm.edu.my/cms/documentstorage/com.tms.cms.document.Document_d7d05d4f-ac12c870-38675e41-18331a55/003 Panduan Pelaksanaan STEM Dalam P\&P.pdf.

Malaysia Commissioner of Law Revision. (1996). Akta Pendidikan 1996, 1996(Akta 550), 92.

Margaret., L. Niess. (2011). Investigating TPACK: Knowledge Growth in Teaching with Technology. Journal of Educational Computing Research, 44(3), $299-317$. https://doi.org/10.2190/EC.44.3.c

Mazalah Ahmad., Jamaludin Badusah., Ahmad Zamri Mansor., Aidah Abdul Karim., Fariza Khalid., Mohd Yusof Daud., \& Rosseni Din., (2016). The Application Of 21st Century ICT Literacy Model Among Teacher Trainees. Turkish Online Journal of Educational Technology, 15(3), 151-161.

Meisalo, V., Lavonen, J., Sormunen, K., Vesisenaho, M., \& Education, T. (2010). ICT in Initial Teacher Training. In Country Report , 1-50.

Meng, Y.L., \& Shuh, S.L. (2011). From Socialisation To Internalisation: Cultivating Technological Pedagogical Content Knowledge Through Problem-Based Learning. Australasian Journal of Educational Technology, 27(1), 89-104. https://doi.org/http://www.ascilite.org.au/ajet/ajet27/tee.html

Ministry of Education and Culture Finland. (2014). Open Science And Research Leads To Surprising Discoveries And Creative Insights: Open Science And Research Roadmap 2014-2017.Retrieved from http://openscience.fi/documents/14273/0/Open+Science+and+Research+Roadmap+2014-2017/e8eb7704-8ea7-48bb92e6-c6c954d4a2f2

Mishra, P., \& Koehler, M. J. (2006). Technological Pedagogical Content Knowledge: A Framework for Integrating Technology in Teacher Knowledge. Teachers College Record, 108(6), 1017-1054. https://doi.org/10.1111/j.1467-9620.2006.00684.x

Muhmmad Abdul Hadi Bunyamin. (2016). Pendidikan STEM Bersepadu: Perspektif Global, Perkembangan Semasa di Malaysia, dan Langkah, (April).

Nazirah Mat Sin, Othman Talib, \& Norishah (2013). Merging Of Game Principles And Learning Strategy Using Apps For Science Subjects To Enhance Student Interest And Understanding. Jurnal Teknologi (Sciences and Engineering), 63(2), 7-12. https://doi.org/10.11113/jt.v63.1998.

Niess, M. L. (2011). Investigating TPACK: Knowledge Growth in Teaching with Technology. Journal of Educational Computing Research, 44(3), 299-317. https://doi.org/10.2190/EC.44.3.c

Nikou, S. A., \& Economides, A. A. (2016). The Impact Of Paper-Based, Computer-Based And Mobile-Based Self-Assessment On Students' Science Motivation And Achievement. Computers in Human Behavior, 55, 1241-1248. https://doi.org/10.1016/j.chb.2015.09.025

Ong Eng Tek \& Shamalah. (2014). Penguasaan Kemahiran Proses Sains Asas dalam Kalangan Murid India di Beberapa Buah Sekolah Rendah di Perak. Sains Humanika 2(1), 135-144.

Peter, F. (2017) Education 4.0. Retrieved from http://www.thegeniusworks.com/2017/01/future-education-young-everyone-taught-together/

PISA. (2016). PISA 2015 Results in Focus. Oecd, 16. https://doi.org/10.1787/9789264266490-

Razali Hassan., Halizah Awang., Badaruddin Ibrahim., \& Siti Hajar Zakariah., (2013). Memacu Pelan Transformasi Pendidikan: Peranan IPTA Dalam Membantu Meningkatkan Kuantiti Dan Kualiti Pendidikan Aliran Sains dan Teknikal di Malaysia. Seminar Kebangsaan Kali Ke-4 Majlis Dekan Pendidikan IPTA 2013, 1127-1142. from Retrieved https://www.researchgate.net/publication/260871374_Memacu_Pelan_Transformasi_Pendidikan_kearah_melahirkan_pelajar_cemerlang_Sains_Teknologi Kejuruteraan.

Sahin, I. (2011). Development of Survey of Technological Pedagogical and Content Knowledge (TPACK). Turkish Online Journal of Educational Technology - TOJET, 10(1), 97-105.

Sánchez-garcía, A., Marcos, J. M., \& Guanlin, H. (2013). Teacher Development and ICT: The Effectiveness of a Training Program for In-Service School Teachers. Procedia - Social and Behavioral Sciences, 92(Lumen), 529-534. https://doi.org/10.1016/j.sbspro.2013.08.713

Seyda Gul., \& Selami Yesilyurt. (2015). The Effect of Computer Assisted Instruction onAchievement and Attitude of Primary School Students. International Online Journal of Educational Sciences, 7(1), 97-109. https://doi.org/10.15345/iojes.2014.03.002

Shikha Kler. (2014). ICT Integration in Teaching and Learning: Empowerment of Education with Technology. Issues and Ideas in Education, $2(2),-271$. https://doi.org/10.15415/iie.2014.22019

Suhaimi, T. (2014). Definisi, Pengertian Dan Makna Motivasi. Retrieved from http://www.ugmc.bizland.com/ak-definisimotivasi.html

Tee, M. Y., \& Lee, S. S. (2011). From Socialisation To Internalisation: Cultivating Technological Pedagogical Content Knowledge Through Problem-Based Learning. Australasian Journal of Educational Technology, 27(1), 89-104. https://doi.org/http://www.ascilite.org.au/ajet/ajet27/tee.html 
The Skop. (2015). Sistem Pendidikan STEM CS dipekenal di Malaysia. http://theskop.com/2015/10/sistem-pendidikan-stem-cs-diperkenal-di-malaysia/ Thinaheswary. (2014). Science Fair for Young Children report. Selangor.

Timmers, C. F., Braber-Van Den Broek, J., \& Van Den Berg, S. M. (2013). Motivational Beliefs, Student Effort, And Feedback Behaviour In Computer-Based Formative Assessment. Computers and Education, 60(1), 25-31. https://doi.org/10.1016/j.compedu.2012.07.007

Zainudin Hassan., Mohd Zaki Mohd Som., \& Nur Azza Abdul Aziz (2015) Reformasi Dan Sistem Pendidikan Di Malaysia, 1(1), 113-126. Retrieved from http://fkip.unismuh.ac.id/e-jurnal/index.php/nusantara/article/view/30/37. 